Judith M. Wenisch, Florian B. Mayr, Alexander O. Spiel, Milko Radicioni, Bernd Jilma* and Petra Jilma-Stohlawetz

\title{
Androgen deprivation decreases prostate specific antigen in the absence of tumor: implications for interpretation of PSA results
}

\begin{abstract}
Background: Prostate-specific antigen (PSA) is used as an outcome measure for relapsed disease in prostate cancer. Nonetheless, there are considerable concerns about its indiscriminate use as a surrogate endpoint for cell growth or survival. We hypothesized that treatment with a luteinizing hormone releasing hormone (LHRH) analog would decrease PSA levels even in the absence of malignant disease.

Methods: We determined testosterone and PSA levels in 30 healthy volunteers after a single intramuscular injection of a LHRH depot formulation. Testosterone and PSA levels were quantified by radioimmunoassay and electrochemi-luminescence immunoassay, respectively.

Results: After an initial flare-up during the first 3 days testosterone decreased reaching castration levels in 18 of the 30 young men $(60 \%)$. After the nadir on day 28 , testosterone levels increased to normal again. Changes in PSA paralleled those of testosterone. Castration reduced PSA levels by $29 \%$ (95\% CI 19\%-39\%) compared to baseline $(\mathrm{p}<0.0001)$.
\end{abstract}

Conclusions: LHRH superagonists decrease PSA levels by testosterone deprivation. Conferring these findings to tumor patients, decreases in PSA after treatment with LHRH analogs might not only reflect disease regression but also a direct testosterone mediated effect on PSA. Thus, PSA levels should be cautiously interpreted when patients receive hormonal therapy.

Keywords: biomarker; clinical trial; leuprolide; luteinizing hormone releasing hormone (LHRH); prostate specific antigen; testosterone.

\footnotetext{
*Corresponding author: Bernd Jilma, MD, Department of Clinical Pharmacology, Medical University of Vienna, Währinger Gürtel 18-20, 1090 Vienna, Austria, Phone: +43 140400 2981, Fax: +431 40400 2998, E-mail: bernd.jilma@meduniwien.ac.at Judith M. Wenisch: Department of Clinical Pharmacology, Division of Immunohematology, Medical University of Vienna, Vienna, Austria; and Department of Hygiene, Wilhelminenspital, Vienna, Austria
}

Florian B. Mayr and Alexander O. Spiel: Department of Clinical Pharmacology, Division of Immunohematology, Medical University of Vienna, Vienna, Austria Milko Radicioni: CROSS SA, Arzo, Switzerland Petra Jilma-Stohlawetz: Department of Laboratory Medicine, Medical University of Vienna, Vienna, Austria

\section{Introduction}

The most reliable way to assess the clinical impact of an intervention is by its effect on a well-defined clinical endpoint. Hard clinical endpoints are the gold standard in efficacy evaluation of an intervention, but the need of long observation periods and large numbers of patients often limit their use in clinical trials. Therefore, biomarkers are increasingly introduced as substitutes in the assessment of clinical responses [1]. A biomarker that is intended to substitute for a clinical endpoint is called a surrogate endpoint. In the best case, biomarkers used as surrogates may improve the efficiency of clinical trials in which long-term disease interventions are evaluated, or enable outcome assessment in situations when meeting the substituted clinical endpoint would be regarded as ethically unacceptable. Nevertheless, it is important to be aware of several limitations in their applicability. According to the criteria for phase III clinical trials developed by Prentice [2], the surrogate should not only be a correlate of the true clinical outcome but fully capture the net effect of treatment on the clinical outcome. This is difficult to fulfil. For example, tissue specificity of prostate specific antigen (PSA) may not be as high as previously assumed, but PSA exists in extremely low concentrations in women [3, 4]. However, this is not clinically relevant in men. It was further shown that for time-to-event endpoints, the Prentice criteria are neither necessary nor sufficient to demonstrate that surrogacy holds true [5].

It was therefore suggested that a biomarker as a surrogate endpoint requires it to be "reasonably likely, based on epidemiologic, therapeutic, pathophysiologic or other evidence, to predict clinical benefit" [6], and a new 
methodology known as the "meta-analytic validation" was developed to verify this [7].

PSA, a member of the family of kallikrein-related peptidases [8], is frequently used for the diagnosis and management of prostate cancer [9] and also as an outcome measure for relapsed disease [10] in prostate cancer trials. However, reliance on PSA kinetics alone may be misleading by several well-known mechanisms [11, 12]. Although it might be assumed that an agent causing a reduction in PSA would do so by reducing tumor burden, it is important to realize that drugs may produce PSA changes through mechanisms other than cell death. Theoretically, a druginduced reduction in the PSA synthesis or an enhanced PSA clearance rate would result in a decrease in PSA. Such effects may confound the value of PSA as predictive for a reduction in tumor size.

Functional androgen response can be found in the proximal promoter of the PSA gene [13]. A direct relationship between androgen level and PSA synthesis on RNA [14] and protein-level has been described in vitro [15] and PSA was suggested to be a useful marker of testosterone activity in vivo [16, 17]. Further, androgen replacement therapy results in modest PSA elevations in healthy old men [18] as well as in men treated for hypogonadism or osteoporosis [19].

Based on these facts and in response to our incidental observations in a clinical trial evaluating a new leuprolide formulation [20], we hypothesized that treatment with a luteinizing hormone releasing hormone (LHRH) superagonist in healthy male volunteers would decrease plasma concentrations of PSA by suppression of testosterone to castration levels. The aim of the study was to assess the effect of a single intramuscular injection of a depot formulation of a LHRH analog on testosterone and PSA levels over 56 days.

\section{Materials and methods}

\section{Subjects and material}

The protocol was approved by the Ethics Committee of the Medical University of Vienna. Written informed consent was obtained from all participants before inclusion. Healthy male subjects aged $18-45$ years with normal body mass index (BMI) and vital parameters were eligible for enrolment. Exclusion criteria were regular or recent intake of medication including steroids in any form, abnormal baseline levels of testosterone or PSA and clinically relevant abnormal findings in medical history, physical examination or laboratory parameters.

On the main study day the 30 participants received a single intramuscular injection of a marketed depot formulation of a LHRH analog (Leuprolide $3.75 \mathrm{mg}$, Enantone ${ }^{\circledR} 3,75$, Takeda Chemical Industries,
Ltd., Japan). Such synthetic LHRH analogs have an increased duration of action and increased affinity for pituitary receptors. This induces down-regulation of the LHRH receptor and a post-receptor desensitization, resulting in reversible biochemical castration and is used as acetate salt to treat a wide range of sex hormone-related disorders, including advanced prostatic cancer. Testosterone and PSA levels were determined at the points of time shown in Figure 1 from blood samples drawn in the morning $(8 \mathrm{AM}+1 \mathrm{~h})$. All samples from each individual were run within one assay.

For testosterone measurements blood was collected in polypropylene tubes, kept at room temperature for $30 \mathrm{~min}$ in order to separate serum and then centrifuged at $1600 \times g$ for $15 \mathrm{~min}$. Serum was collected, divided in aliquots and stored at $-70^{\circ} \mathrm{C}$ pending analysis. Samples packed in sufficient solid carbon dioxide, were shipped by an authorized courier to Bio-Inova France for analysis. Testosterone
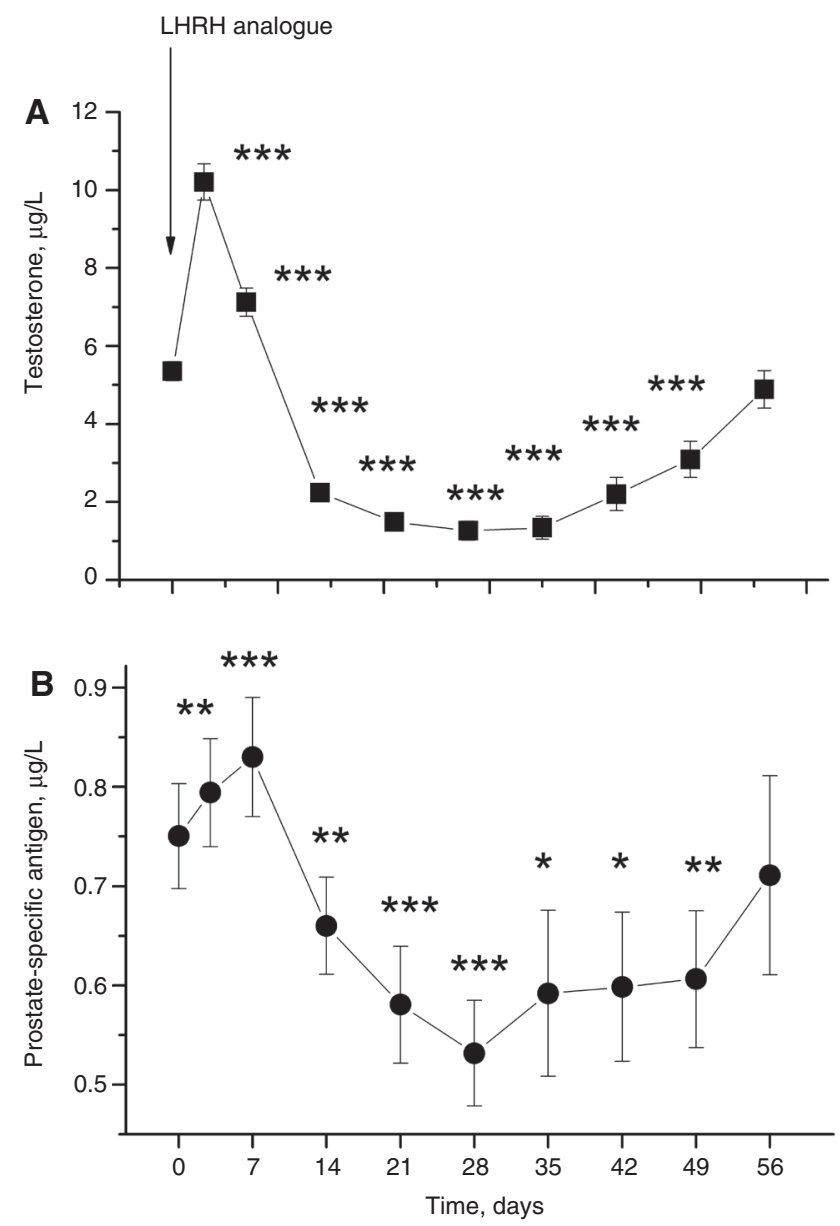

Figure 1 Testosterone and prostate specific antigen (PSA) levels in healthy male volunteers $(n=30)$ after a single intramuscular injection of leuprolide.

(A) After an initial flare-up during the first 3 days, testosterone levels decreased and reached castration levels by day 21 . After the nadir on day 28, testosterone levels increased again to baseline levels. (B) The initial increase in PSA levels occurred concomitantly with the increase in testosterone levels. The nadir was also reached on day 28. Thereafter PSA levels rose again to normal values. Data presented as means $\pm S E M,{ }^{*} p<0.05$, ${ }^{\star \star} p<0.01$, ${ }^{\star \star \star} p<0.001$. 
levels were determined by radioimmunoassay (Behring Diagnostic; total precision: coefficient of variation $<15 \%$ ).

For the determination of total PSA blood was collected into tubes with separation gel and centrifuged at $3500 \times g$ and $25^{\circ} \mathrm{C}$ for $10 \mathrm{~min}$. PSA was then determined by an electrochemiluminescence immunoassay "ECLIA" on the Roche Elecsys 2010 (Roche Diagnostics $\mathrm{GmbH}$, Mannheim, Germany; intra-assay CV<3\%) [21].

\section{Data analysis and visualization}

For descriptive purposes, data are presented as means and standard deviations (SD), unless stated otherwise. The Friedman ANOVA and the Wilcoxon test were applied using Statistica 6.0 software (StatSoft Inc). Figures were created with Origin 7.0 (Origin Lab, Northampton, MA, USA).

\section{Results}

Baseline characteristics of the 30 healthy young males (mean age: $27 \pm 5$ years) are shown in Table 1. Figure 1 shows the kinetics of testosterone and PSA levels in the men treated with a LHRH analog on day 0 .

The expected "flare-up" effect in testosterone was reflected by an initial increase, which reached the maximum on day 3. Thereafter, testosterone concentrations dropped to nadir values reached on day 28 $(\mathrm{p}<0.0001)$. Castration (i.e., testosterone $<0.5 \mathrm{ng} / \mathrm{mL}$ ) was reached in 18 out of 30 males (60\%). After day 35 the subjects began to recover from castration and reached baseline levels by day 56 ( $\mathrm{p}=0.46$ compared to baseline).

PSA levels followed the changes in testosterone, first with a time lag of 3-7 days: after an initial slight rise with a maximum on day 7 they transiently decreased. The nadir was also reached on day 28, when PSA levels were reduced by $29 \%$ (95\% CI 19\%-39\%, p<0.0001 vs. baseline). Thereafter, PSA levels rose again, normalizing by day 56 .

Table 1 Baseline characteristics.

\begin{tabular}{ll}
\hline \multicolumn{2}{l}{ Baseline characteristics of the $\mathbf{3 0}$ healthy men } \\
\hline Age, years & $27 \pm 5$ \\
Body weight, $\mathrm{kg}$ & $76.6 \pm 9.2$ \\
Height, $\mathrm{cm}$ & $178 \pm 7$ \\
$\mathrm{BMI}, \mathrm{kg} / \mathrm{m}^{2}$ & $24.1 \pm 2.5$ \\
Systolic BP, mm Hg & $126 \pm 9$ \\
Diastolic BP, mm Hg & $70 \pm 10$ \\
Heart rate, bpm & $73 \pm 9$ \\
Testosterone, $\mu \mathrm{g} / \mathrm{L}$ & $5.4 \pm 1.3$ \\
PSA, $\mu \mathrm{g} / \mathrm{L}$ & $0.75 \pm 0.29$ \\
\hline
\end{tabular}

Data presented as means \pm SD. BMI, body mass index; BP, blood pressure; PSA, prostate- specific antigen.

\section{Discussion}

In patients with prostate cancer the decline in PSA after therapy with LHRH analogs is regarded as a sign of disease regression $[22,23]$. This was the first trial to prospectively examine the influence of an LHRH analog on PSA levels. The data demonstrate a rapid response to LHRH in the sense of a pronounced decrease in PSA by approximately $30 \%$ in the absence of malignant disease. This decrease in PSA levels in healthy young male volunteers can certainly not be explained by tumor cell death or shrinkage of a prostatic hyperplasia, but might reflect an effect on cell metabolism by testosterone deprivation. However, when LHRH superagonists are used for the treatment of precocious puberty, they hold the further development of gonads and prolonged treatment of animals with LHRH superagonists may lead to reversible shrinkage of the testicles [24]. Although early trials in humans have indicated that LHRH analogs are not clinically effective for the treatment of benign hypertrophic prostate [25], LHRH agonists or antagonists may reversibly reduce prostate size in animals [26, 27]. However, the rapid flare-up in testosterone and consequently PSA cannot be due to shrinkage of the prostate and the rapid fall in PSA on day 14 after initiation of treatment is unlikely a consequence of prostate shrinkage which would be assumed to occur later.

The biomarker PSA seems to be directly affected by the intervention, i.e., treatment with the LHRH analog. In tumor patients LHRH analogs might similarly exert their effect on PSA not exclusively by influencing the disease, and an initial decrease in PSA levels might therefore not necessarily reflect treatment success. Indeed, there is evidence to suggest that androgen deprivation therapy (ADT) causes the initial decrease in PSA, not only because of tumor regression, but also because of suppression of androgen-dependent PSA gene transcription [28, 29]. The confirmed PSA suppression in the 30 healthy volunteers supports this hypothesis.

The phenomenon that declines in PSA levels might simply reflect the effect of the drug on the marker instead of an effect on cell growth or survival was also described for finasteride [30]. Finasteride is a $5 \alpha$-reductase inhibitor, which decreased PSA levels by $50 \%$ in elderly men (mean age: $64 \pm 9$ years) treated for benign prostatic hyperplasia for 12 months [31]. Finasteride use was associated with less but higher-grade prostate cancer in the Prostate Cancer Prevention Trial, which led to several speculations regarding bias introduced by treatment induced PSA reduction [32]. It is essential to understand and document a drug's effect on PSA, since pure effects on PSA 
production without any influence on tumor growth have been shown for potential cytotoxic drugs in phase II clinical trials [33]. In both, prevention and treatment, changes in PSA are difficult to interpret, especially if they are influenced by the intervention. It was therefore recommended that declines in PSA should be documented over time [34]. The studies on PSA velocity and other dynamic measures of PSA changes suggest that these might be more powerful than classical definitions of PSA changes using threshold values [35].

In the interpretation of PSA kinetics in clinical drug trials, the mechanism by which a drug exerts its effect on the tumor should be taken into account, as its influence on PSA may vary depending on whether a drug is directly cytotoxic or influences hormonal growth regulation. Further, a drug-induced change in PSA might occur with or without a delay after treatment initiation. It was recommended that phase II or III clinical trials should be designed in a way that the PSA endpoint matches the anticipated effect of the tested drugs on PSA levels [35]. Therefore, PSA changes should routinely be documented even in phase I clinical trials to differentiate drug from treatment effects.

The question arises how our findings relate to tumor patients treated with LHRH analogs. In particular, baseline PSA levels might not be reliable before day 28 after initiation of LHRH analog treatment. Repeated measurements should be performed until the nadir is reached and an increase thereafter should be interpreted with caution. Clinicians using LHRH superagonists should not rely on PSA levels alone to judge clinical benefits, in agreement with the current recommendation not to use PSA endpoints in phase III trials [35].

One practical issue has to be considered: PSA with its extremely low detection limit of $0.01 \mathrm{ng} / \mathrm{mL}$ detects much earlier growing tumor cells than imaging. A PSA rise after prostate cancer therapy (operation, radiation, even LHRH therapy) from $<0.01$ to 0.2 cannot be detected by image diagnostics. In that seldom case that PSA levels remain low but stable after therapy there is a high probability that this PSA level is related to benign tissue PSA production. However, this conclusion can be drawn from the patient's follow-up and his PSA levels.

PSA doubling time and velocity have mostly been studied for testing chemotherapeutic agents against hormone refractory prostate cancer and need further validation for their use in hormonally treated patients $[35,36]$.

It may be possible from a biochemical view that the PSA decrease after LHRH therapy may not be a treatment effect, but the question remains whether this could be clinically relevant. Mainly patients with advanced prostate cancer receive LHRH, who have often undergone prostatectomy. It is clinically unimportant if there is a small rest of regular prostate tissue that is also affected by the LHRH. The PSA doubling time for patients with regular prostate tissue is lower than the doubling time in tumor patients that need LHRH. Therefore this effect could be due to benign tissue only in those patients with remaining low PSA levels over a very long time (after treatment of their prostate cancer). However, it is unknown whether PSA in cancer cells is also under direct regulation of androgens as in normal prostate cells.

It is perhaps somewhat surprising that in only 18 out of 30 men castration levels of testosterone were reached, although the LHRH superagonists should guarantee a castration level under regular clinical conditions. However this observation is consistent with the failure of another leuprolide product (Lucrin $3.75 \mathrm{mg}$ ) to lower testosterone levels below $0.5 \mathrm{ng} / \mathrm{mL}$ in three out of five healthy volunteers [20], and the failure of triptorelin to suppress testosterone levels in some treated patients [37]. This indicates that the lower leuprolide release from products of lower strength (3.75 mg instead of $7.5 \mathrm{mg}$ ) may be insufficient at least in younger subjects.

A potential limitation of this trial is that we have only measured total PSA (i.e., free and complexed PSA). Although, free PSA decreases more rapidly after prostatectomy and LHRH antagonists [38] than complexed PSA, all forms of PSA show a similar kinetics, i.e., a slow and parallel decrease after initiation of hormonal treatment with LHRH analogs [39].

In summary, LHRH superagonists rapidly decrease PSA levels by testosterone deprivation. Thus, PSA levels should be interpreted with caution in patients receiving hormonal therapy.

Acknowledgments: We thank Sabine Schranz, RN for her invaluable contribution.

\section{Conflict of interest statement}

Authors' conflict of interest disclosure: The authors stated that there are no conflicts of interest regarding the publication of this article.

Research funding: None declared.

Employment or leadership: None declared.

Honorarium: None declared.

Received July 12, 2013; accepted September 19, 2013; previously published online October 12, 2013 


\section{References}

1. Biomarkers Definitions Working Group. Biomarkers and surrogate endpoints: preferred definitions and conceptual framework. Clin Pharmacol Ther 2001;69:89-95.

2. Prentice RL. Surrogate endpoints in clinical trials: definition and operational criteria. Stat Med 1989;8:431-40.

3. Diamandis EP. Prostate-specific antigen: a cancer fighter and a valuable messenger? Clin Chem 2000;46:896-900.

4. Zarghami N, Grass L, Sauter ER, Diamandis EP. Prostatespecific antigen in serum during the menstrual cycle. Clin Chem 1997;43:1862-7.

5. Buyse M, Molenberghs G. Criteria for the validation of surrogate endpoints in randomized experiments. Biometrics 1998;54:1014-29.

6. MacGregor JT, Farr S, Tucker JD, Heddle JA, Tice RR, Turteltaub KW. New molecular endpoints and methods for routine toxicity testing. Fundam Appl Toxicol 1995;26:156-73.

7. Daniels MJ, Hughes MD. Meta-analysis for the evaluation of potential surrogate markers. Stat Med 1997;16:1965-82.

8. Kontos CK, Scorilas A. Kallikrein-related peptidases (KLKs): A gene family of novel cancer biomarkers. Clin Chem Lab Med 2012;50:1877-91.

9. Hoffman RM, Zeliadt SB. The cautionary tale of PSA testing. Arch Intern Med 2010;170:1262-3.

10. Melichar B. Tumor biomarkers: PSA and beyond. Clin Chem Lab Med 2012;50:1865-9.

11. Fleming MT, Morris MJ, Heller G, Scher HI. Post-therapy changes in PSA as an outcome measure in prostate cancer clinical trials. Nat Clin Pract Oncol 2006;3:658-67.

12. Fleming TR, DeMets DL. Surrogate end points in clinical trials: are we being misled? Ann Intern Med 1996;125:605-13.

13. Cleutjens KB, van der Korput HA, Ehren-van Eekelen CC, Sikes RA, Fasciana C, Chung LW, et al. A 6-kb promoter fragment mimics in transgenic mice the prostate-specific and androgen-regulated expression of the endogenous prostate-specific antigen gene in humans. Mol Endocrinol 1997;11:1256-65.

14. Henttu P, Vihko P. Prostate-specific antigen and human glandular kallikrein: two kallikreins of the human prostate. Ann Med 1994;26:157-64.

15. Peehl DM. Prostate specific antigen role and function. Cancer (Suppl) 1995;75:2021-6.

16. Juul A, Muller J, Skakkebaek NE. Prostate specific antigen in boys with precocious puberty before and during gonadal suppression by GnRH agonist treatment. Eur J Endocrinol 1997;136:401-5.

17. Vieira JG, Nishida SK, Pereira AB, Arraes RF, Verreschi IT. Serum levels of prostate-specific antigen in normal boys throughout puberty. J Clin Endocrinol Metab 1994;78: 1185-7.

18. Tenover JS. Effects of testosterone supplementation in the aging male. J Clin Endocrinol Metab 1992;75:1092-8.

19. Amory JK, Watts NB, Easley KA, Sutton PR, Anawalt BD, Matsumoto AM, et al. Exogenous testosterone or testosterone with finasteride increases bone mineral density in older men with low serum testosterone. J Clin Endocrinol Metab 2004;89:503-10.

20. Leitner JM, Mayr FB, Spiel AO, Firbas C, Savulsky C, Mis R, et al. The pharmacokinetics and pharmacodynamics of a new sustained-release leuprolide acetate depot compared to market references. Int J Clin Pharmacol Ther 2008;46:407-14.

21. Stephan C, Klaas M, Muller C, Schnorr D, Loening SA, Jung K. Interchangeability of measurements of total and free prostatespecific antigen in serum with 5 frequently used assay combinations: an update. Clin Chem 2006;52:59-64.

22. Tunn UW, Bargelloni U, Cosciani S, Fiaccavento G, Guazzieri S, Pagano F. Comparison of LH-RH analogue 1-month depot and 3-month depot by their hormone levels and pharmacokinetic profile in patients with advanced prostate cancer. Urol Int 1998;60(Suppl 1):9-16; discussion 7.

23. Raina R, Pahalajani G, Agarwal A, Zippe C. Long-term effectiveness of luteinizing hormone-releasing hormone agonist or antiandrogen monotherapy in elderly men with localized prostate cancer (T1-2): A retrospective study. Asian J Androl 2007;9:253-8.

24. Junaidi A, Williamson PE, Trigg TE, Cummins JM, Martin GB. Morphological study of the effects of the GnRH superagonist. deslorelin on the canine testis and prostate gland. Reprod Domest Anim 2009;44:757-63.

25. Keane PF, Timoney AG, Kiely E, Williams G, Stamp G. Response of the benign hypertrophied prostate to treatment with an LHRH analogue. Br J Urol 1988;62:163-5.

26. Vickery BH, McRae GI, Bonasch H. Effect of chronic administration of a highly potent LHRH agonist on prostate size and. secretory function in geriatric dogs. Prostate 1982;3: 123-30.

27. Rick FG, Schally AV, Block NL, Halmos G, Perez R, Fernandez JB, et al. LHRH antagonist Cetrorelix reduces prostate size and gene expression of proinflammatory cytokines and growth factors in a rat model of benign prostatic hyperplasia. Prostate 2011;71:736-47.

28. Lilja H, Ulmert D, Vickers AJ. Prostate-specific antigen and. prostate cancer: Prediction, detection and monitoring. Nat Rev Cancer 2008;8:268-78.

29. Ryan CJ, Smith A, Lal P, Satagopan J, Reuter V, Scardino P, et al. Persistent prostate-specific antigen expression after neoadjuvant androgen depletion: An early predictor of relapse or incomplete androgen suppression. Urology 2006;68:834-9.

30. Etzioni RD, Howlader N, Shaw PA, Ankerst DP, Penson DF, Goodman PJ, et al. Long-term effects of finasteride on prostate specific antigen levels: Results from the prostate cancer prevention trial. J Urol 2005;174:877-81.

31. Byrnes CA, Liss CL, Tenover JL, Lippert MC, Gillenwater JY. Combined analysis of two multicenter studies of finasteride $5 \mathrm{mg}$ in the treatment of symptomatic benign prostatic hyperplasia. Prostate Cancer Prostatic Dis 1997; 1:26-31.

32. Thompson IM, Goodman PJ, Tangen CM, Lucia MS, Miller GJ, Ford LG, et al. The influence of finasteride on the development of prostate cancer. N Engl J Med 2003;349:215-24.

33. Thalmann GN, Sikes RA, Chang SM, Johnston DA, von Eschenbach AC, Chung LW. Suramin-induced decrease in prostate-specific antigen expression with no effect on tumor growth in the LNCaP model of human prostate cancer. J Natl Cancer Inst 1996;88:794-801. 
34. Scher HI, Mazumdar M, Kelly WK. Clinical trials in relapsed prostate cancer: Defining the target. J Natl Cancer Inst 1996;88:1623-34.

35. Collette L, Burzykowski T, Schroder FH. Prostate-specific antigen (PSA) alone is not an appropriate surrogate marker of long-term therapeutic benefit in prostate cancer trials. Eur J Cancer 2006;42:1344-50.

36. D’Amico AV, Moul JW, Carroll PR, Cote K, Sun L, Lubeck D, et al. Intermediate end point for prostate cancer-specific mortality following salvage hormonal therapy for prostatespecific antigen failure. J Natl Cancer Inst 2004;96: 509-15.

37. Jilma B, Eichler HG, Koppl C, Weber B, Pidlich JP, Ferenci P, et al. Effects of testosterone suppression on serum levels of hepatitis B surface antigen and HBV-DNA in men. Liver 1998;18:162-5.

38. Ulmert D, Vickers AJ, Scher HI, Becker C, Iversen P, Frankel D, et al. Rapid elimination kinetics of free PSA or human kallikreinrelated peptidase 2 after initiation of gonadotropin-releasing hormone-antagonist treatment of prostate cancer: Potential for rapid monitoring of treatment responses. Clin Chem Lab Med 2012;50:1993-8.

39. Bjork T, Schalken J, Wittjes W, Ljungberg B, Lilja H. Similar rates of exponential decrease in serum concentrations of free prostate-specific antigen (PSA), PSA complexed to alpha1-antichymotrypsin, and human glandular kallikrein 2 (hK2) in prostate cancer patients treated with $\mathrm{GnRH}$-analogues. Prostate 2001;47:14-20. 